Henry, J. A. (1991) Overdose and safety with fluvoxamine. International Clinical Psychopharmacology, 6 (suppl. 3), 41-47.

D. Amital H. Amital R. Gross

S. KINDLER

J. ZOHAR

Sheba Medical Center

Tel-Hashomer 52621, Israel

\section{Treatment of drug-induced anorgasmia}

SIR: Arnott \& Nutt (BJP, June 1994, 164, 838-839) reported the treatment of fluvoxamine-induced anorgasmia with cyproheptadine. Fluoxetineinduced anorgasmia has been successfully reversed with both cyproheptadine and yohimbine, an alpha-2 antagonist (Segraves, 1993). I would like to report the successful treatment of six cases of sertraline-induced anorgasmia ( 2 men, 4 women) and four cases due to paroxetine ( 3 men, 1 woman), with $5.4 \mathrm{mg}$ yohimbine taken approximately 1-2 hours prior to planned coitus. To date, all cases of serotonin reuptake inhibitor-induced anorgasmia encountered in my practice have responded to small, appropriately timed doses of yohimbine.

Segraves, R. T. (1993) Treatment-emergent sexual dysfunction in affective disorder. Journal of Clinical Psychiatry, 11 (monograph 1), $1-4$.

Case Western Reserve University

Robert Taylor Segraves

Cleveland, Ohio 44122

\section{Violence in psychiatric units}

SIR: Studying violent incidents in psychiatric units, Walker \& Seifert (BJP, June 1994, 164, 826-828) found that nurses were assaulted most often. Nurses make up the majority of the staff on most psychiatric units, and the greater frequency of assault may simply reflect their greater numbers and increased patient contact.

The authors suggest that a forensic history is a predictor of violent behaviour as an in-patient, and that this should be used as an indication that these patients should receive extra attention. Taking this as a screening test, where a forensic history is used as an indicator, a forensic history provided a sensitivity of 0.81 and a specificity of 0.69 . Predictive values are of greater use in assessing the value of a screening test in routine practice and the positive predictive value of a forensic history in this population was 0.56 (i.e. $56 \%$ of those with a forensic history would assault). In effect, the use of this as a screening test would result in twice as many patients being identified as potentially assaultive as would eventually assault. Our concern would be that staff would recognise that the forensic history was a blunt predictive instrument, and would relax their vigilance over time.

Walker \& Siefert's work confirms the frequency of violent behaviour, and emphasises the need for appropriate training. The limited help provided by aspects of the clinical history lead us to believe that it is essential to strive to develop safe systems. Rather than staff relying on the identification of high risk patients, ward and hospital management should endeavour to create safe environments by the appropriate use of observation, alarm systems, staff support and training.

Cameron Stark

Department of Public Health

HEATHER FARRAR

Paisley PA2 7BN

Tone Vale Hospital, Taunton

BRIAN KIDD

\section{Male erotomania and dangerousness}

SIR: Boast \& Coid (BJP, June 1994, 164, 842-846) describe a case of male homosexual erotomania featuring dangerous behaviour directed at the delusional object, and comment that the question of dangerousness in such cases remains unresolved.

When discussing dangerousness in relation to erotomanic delusions it is useful to distinguish between dangerous behaviour related to the delusions, such as assault on the object or 'rival', and unrelated dangerous behaviour which may precede the onset of the delusions. In a sample of 27 cases of men with erotomanic features (Menzies et al, in press), we found that dangerousness (related to the delusions) was significantly associated with both the presence of multiple delusional objects $(P<0.0005)$ and dangerousness unrelated to any erotomanic delusion $(P<0.05)$. The only cases which exhibited dangerous behaviour (related) had either multiple delusional objects $(42 \%)$ or a history of unrelated dangerous behaviour $(25 \%)$ or both $(33 \%)$.

Boast \& Coid did not report any other delusional attachments in their case but there was a history of an assault, unrelated to the erotomanic delusion, and an additional diagnosis of personality disorder. They referred to two other cases of male homosexual erotomania. One (Doust \& Christie, 1978), with a single object, exhibited no dangerous behaviour, while the other (Peterson \& Davis, 1985), with 